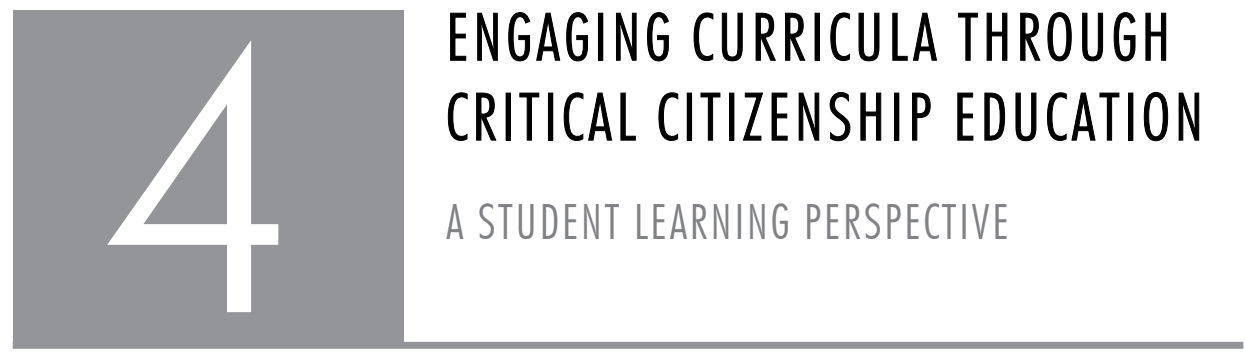

\title{
INTRODUCTION
}

In the previous chapters we have shown that numerous curriculum challenges remain in higher education - not only in South Africa, but worldwide. One such challenge is to provide a critical citizenship perspective to curricula that may contribute to educate for more democratic and sustainable environments. We have also drawn on Giroux's views on critical pedagogy and engaged curricula as a potentially useful lens to relate critical citizenship to critical pedagogy. Lastly, we have pointed out that in South Africa, although important higher education policy initiatives had materialised after 1994, much work remains to promote critical citizenship in higher education curricula.

At least four elements of learning seem to inform critical citizenship education in curricula, namely psychosocial, transformational, socio-political and multicultural learning. One may also refer here to theories of learning, but what we do realise, however, is that the forces interacting and wrestling for power in constructing curricula that engage students on the one hand, but also keep such curricula vibrant on the other hand, are numerous, complex and ever-shifting. This we want to allude to in the sections that follow.

Engaging university curricula via a critical citizenship education perspective requires involved lecturers, involved and engaged students and, also importantly, involved curriculum researchers. Drawing on some earlier work of Coldstream (2003) and Barnett (2003), Boland and Mcllrath (2007:84-85) describe the action of engaging curricula as follows:

[...] engagement infers mutual listening, reciprocity and dialogue which is focused on something beyond the self. It comprehends both a promise 
of action and the outcome of action. [...] [Curriculum] engagement is full of potential, promise, risk and uncertainty, often because it entails a willingness to change. It entails accommodating the other and preparedness to be transformed in the process. It is concerned with strenuous, thoughtful, argumentative interaction with the wider world.

This definition links well with Barnett's (2000) earlier plea for university curricula to be grounded in student engagement that includes knowing (intellectual engagement), doing (practical engagement) and communicating (engaging with others). A more recent grounding involve three areas of engagement, namely knowing, acting and being (Barnett \& Coate 2005), concluding that, even though a curriculum can be considered as engaged, it is only via "pedagogies of engagement", through teaching approaches and pedagogical relationships between lecturers and students, that an engaged curriculum is actually realised.

Taking its cue from Barnett and Coate (2005), a critical citizenship education perspective on curricula aims to involve students on deeper levels of learning, which include emotional and social aspects of learning. Such learning does not solely focus on discipline-specific content, but extends to both critical self-reflection and the critical action that follows this reflection. In this way, a critical citizenship education perspective on curricula contains a number of pertinent elements related to prominent learning theories such as psychosocial, adult, socio-political and multicultural learning; all important for taking a critical citizenship education perspective on curricula, which we briefly explore in the rest of this chapter.

\section{PSYCHOSOCIAL ELEMENTS OF LEARNING}

It is widely accepted that learning cannot be separated from feelings and emotions. Illeris (2003a, 2003b) has suggested a comprehensive framework of learning providing a distinction between the three dimensions of learning, namely cognitive, emotional and societal learning. In its triangular form (see Figure 4.1), the top axis is presented as ranging between the cognitive and the emotional; often labelled as related to the psychology of development. The contributions of cognitive psychologists such as Piaget and Kolb are positioned towards the cognitive pole, whereas those of Freud and Rogers are positioned towards the emotional pole (Illeris 2003a). The left side of the triangle links towards the societal pole, where Bruner's later work is relevant (Illeris 2003a), while the right side returns to the emotional pole. Moving from the societal to the emotional pole, Illeris (2003a) highlights the critical theory contribution of philosophers such as Adorno, Horkheimer and Marcuse. The contributions of Habermas (1978) are furthermore highlighted as connecting the theories of society and emotion with the work of Marx and psychoanalysis. The 
significance of such a comprehensive framework is that it connects meaning-making (cognition), sensitivity (emotion) and sociality (society) within learning as a holistic trajectory and rejects a separation of learning in different contexts such as the formal, informal, personal, developmental, social and the like (Illeris 2003a:397).

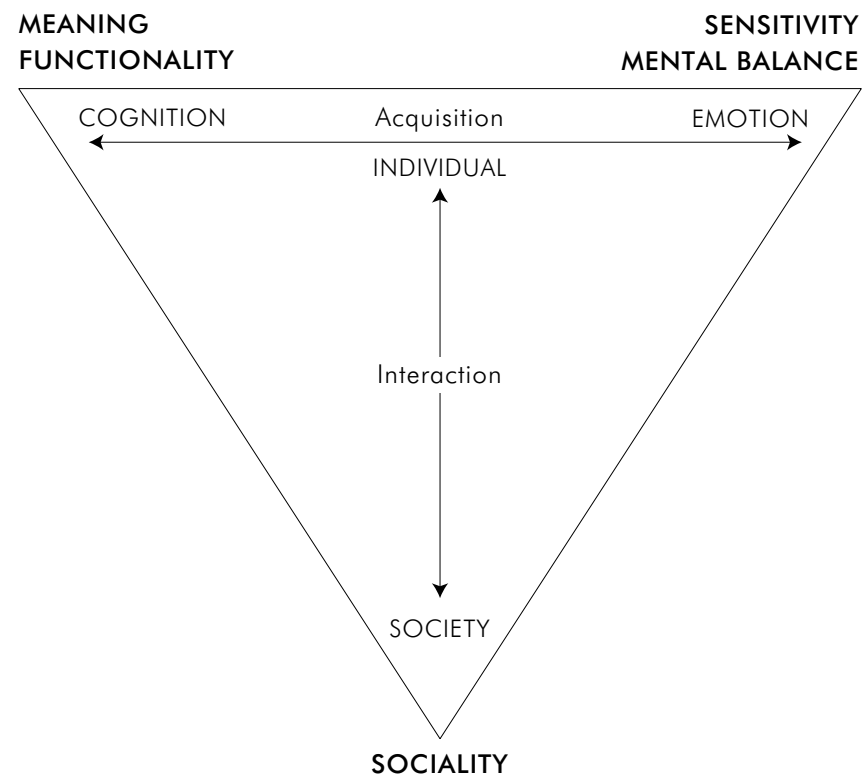

FIGURE 4.1 Three dimensions of learning (after Illeris 2003b:171)1

The cognitive dimension of learning is described by Illeris (2003a) as learning content, or the knowledge or skill that informs understanding, meaning-making or ability. The emotional dimension represents feelings and motivations, and consequently its function is to secure mental balance in order to enable and promote learning (Illeris 2003a:399). Illeris (2003a:399) stresses that "all cognitive learning is, so to speak, 'obsessed' by the emotions at stake". Emotional learning, in the same way, is always influenced by cognitive understanding. This close connection between emotion and cognitive understanding has been researched at length in the field of neurology, which we briefly touch upon, and may therefore provide some explanation why cognition and emotion both prove valuable in critical citizenship education.

1 Illeris created a similar framework where the word "society" was replaced with "environment" and then added a circle around the triangle to indicate "society" (see Illeris 2003a:400). For the purpose of this book we use the Illeris (2003b: 171) framework, as it better illustrates what was brought across in the examples discussed in Chapter 5. 


\section{Neurological explanations for the cognitive-emotional link}

A closer look at the human central nervous system reveals that the body's decision and communication centre consists of the brain and the spinal cord. Emotions originate in the amygdala, which is situated above the brain stem and near the bottom of the limbic system (Jarvis 2006). Research has identified the neocortex as the part of the brain where thinking occurs. In all mammals, the neocortex is involved in higher cognitive functions. These include sensory perception, the generation of motor commands, spatial reasoning and conscious thought and language (Lui, Hansen \& Kriegstein 2011). According to Goleman (2004:15), the amygdala can be viewed as the "storehouse" of emotional memory, while he also argues that "life without the amygdala is a life stripped of personal meaning".

Physical sensations are sent to the thalamus, a midline symmetrical structure within the brain, which functions include not only relaying sensory and motor signals to the cerebral cortex, but also the regulation of consciousness, sleep and alertness (Sherman 2006). These sensations are then relayed to the neucortex and the amygdala. Of these, the amygdala reacts more rapidly, often causing an immediate emotional reaction to stimuli. Interestingly, Goleman (1996:15) uses the term "amygdala hijack" to describe immediate emotional responses from people that are overwhelming to the extent that they do not correlate with the actual stimulus, due to the fact that it has triggered a much more significant emotional threat. In his work, Goleman (1996) refers to the research of the neuroscientist LeDoux, who found that the emotional brain, as in the case of "amygdala hijack", can overpower the thinking brain and consequently, emotions such as anger or stress can impede rational thinking. As such, the "thinking brain" or neocortex, often balances or corrects the emotional brain moments later.

The significant link between the amygdala and emotion is clearly demonstrated when the amygdala is isolated, for instance, in surgery. In such a situation, the brain becomes computer-like and the person is unable to feel or be decisive (Goleman 1996). Emotions, in this sense, can be seen as our driving forces - very often giving rise to our actions (Barbalet 2001:81). Because emotions play such a pivotal role in our actions, Reanney (1991) suggests that selfish egos come from selfish genes and humans, almost above all else, dread changes that deeply modify, reshape and remake the ego-self. Furthermore, it is a human instinct to protect oneself from personal emotional change, otherwise we become other to ourselves and our lens to the world could be shattered (Reanney 1991). Consequently, there may develop a tendency to avoid learning that involves emotional and personal shifts or changes. 
Earlier we referred to Illeris's (2003b: 171) three dimensions of learning illustrated by an inverted triangular diagram (see Figure 4.1) in which the interaction between the cognitive, emotional and social is indicated. At this point we would like to propose that this interaction could be portrayed differently, based on the functions of the human brain. This alternative representation is depicted in Figure 4.2. The brain consists of the brain stem, which controls all organs that sustain life, the limbic system, where the emotions are situated, and the neocortex, where reasoning, language and imagination is located (Reanney 1991) (see Figure 4.3).

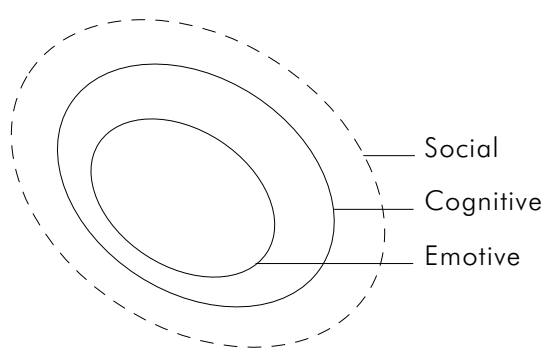

FIGURE 4.2 Dimensions of learning (adapted from Illeris 2003b:171)

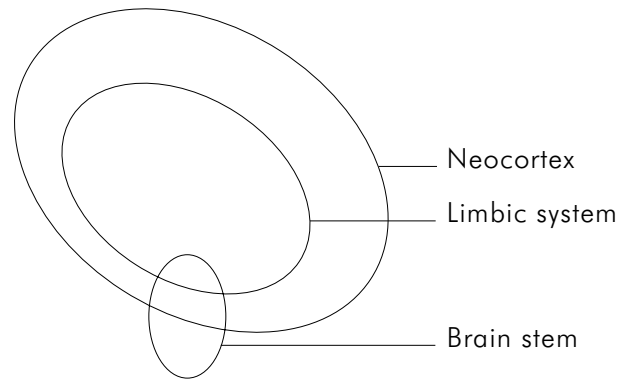

FIGURE 4.3 The composition of the three interlocking parts of the brain

Through evolution, the brain has developed in that order: stem, limbic (both prehuman) and the human neocortex. Our reason for adjusting the structure portrayed by Illeris's (2003b:171) dimensions is based on the interconnectedness of the emotional and cognitive aspects of the brain. As mentioned earlier, with reference to Goleman (1996), the emotional reaction often occurs before the cognitive, with the cognitive subsequently correcting the emotional. However, when responding to sensations, more than the two poles of cognitive and emotional that interact is 
involved. It is therefore important to understand the effect of emotions on human actions and how the cognitive might only react to stimuli seconds or even days later. ${ }^{2}$ Barnett et al. (2001:445) argue that, apart from the knowledge and skills that are developed in education, one should also look at the person of the learner or student. Barnett and Coate (2005:59-64) further propose that curriculum engagement implies three basic building blocks: knowing, acting and being, whereby "an act of knowing is a positional and personal act" and "an act of knowledge calls for a public act in which the individual shows herself, proclaims herself" (Barnett \& Coate 2005:60). Knowledge therefore involves both the personal and the social. In this theory there is also a relationship between knowing and being. The concept of the self, being or becoming, is emphasised, which relates to self-realisation, selfconfidence and self-understanding (Barnett \& Coate 2005:63).

It therefore seems clear that critical citizenship education cannot take place in any curriculum without considering the diversity of the inner lives of students - even more so because of the traumatic and confusing apartheid past in South Africa. Barnett and Coate (2005:1 19) stress that the forms of life that are now encouraged are increasingly those of "being-in-the-world", rather than forms of "being-inknowledge". The ability of students to be resilient and sustain themselves emotionally in the world therefore becomes increasingly important. Subsequently, the need for these abilities calls for not only content- and field-specific knowledge, but also for more of a "curriculum of life" (Barnett \& Coate 2005:1 19) that prepares a student academically, socially and emotionally. This brings to the fore elements of adult and transformative learning or, learning for and in adulthood, which we briefly touch upon next.

\section{ELEMENTS OF ADULT LEARNING}

From an adult learning perspective and based on the assumption that university students are adults-in-the-making with an emerging awareness of citizenship, we refer to Jarvis (2006), who aims to understand human learning and addresses issues of being, becoming and learning throughout life. Jarvis (2006:14) asserts that "[p]ersonhood is at the heart of our understanding of learning", and that "it is not possible to separate reason from passion" if it is agreed that human beings are thinking, feeling and acting beings. Jarvis (2006:22-23) points to "the personin-the-world", but from the perspective of transforming the person experiencing

2 Illeris (2003a:339) remarks that emotional learning is always affected by cognition and understanding, explaining that new information can change the emotional condition, and also refers to studies by the neurologist Damasio (1994). 
the world. He therefore suggests a model (see Figure 4.4) that illustrates that mind and body are simultaneously incorporated in the transformational learning process. As learners we therefore transform our experiences - not only through cognitive thinking, but also through our emotions and actions.

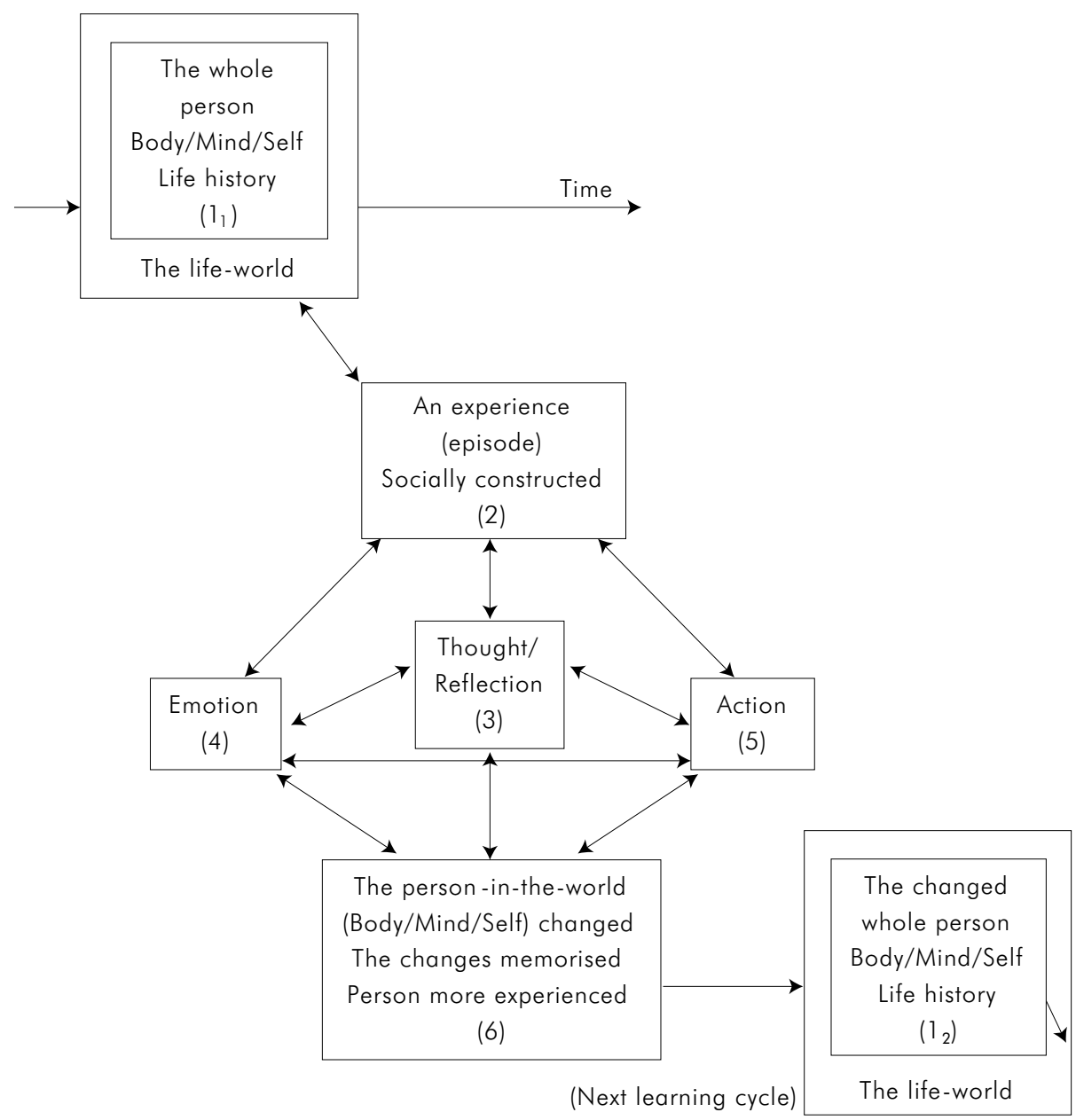

FIGURE 4.4 Transforming the person experiencing the world (after Jarvis 2006:23)

Figure 4.4 suggests that the whole person, including the body, the mind and the self with its own life history, experiences learning impulses. A person responds to such impulses by taking in the information and then responds with a certain emotion (depending on his/her own life history), reflects on it (within seconds or days) and then reacts to it. It is a process of transforming and internalising experience, which is a 
body-mind relationship (Jarvis 2006:22). Figure 4.4 therefore describes the process of a person that experienced a learning impulse that resulted in a changed person, which is then repeated when the changed person is exposed to new impulses.

Jarvis also refers to Cell's types of experience that generate an emotional response, namely functional, dysfunctional and the profound (Jarvis 2006:109). The functional refers to "our interpretations [that] focus upon our sense of self and it is these that give rise to sensations and action tendencies" in a positive sense (Jarvis 2006:109). Dysfunctional emotions also affect the sense of self but do so in a negative way. Profound emotions are beyond our immediate understanding and lead to contemplation (Jarvis 2006:110). These combinations of thinking, feeling and acting are successively stored, and are later drawn upon in future learning experiences.

Also linked to how emotions impact on adult learning, Thoits (1989:319) has pointed to two approaches to emotion: the micro level (social psychological) and the macro level (structural-cultural) approach. Structural-cultural emotional experiences at the macro level, which may include the political and economic life spheres, could play a role in the way we express our emotions. Hargreaves (1998:836) further emphasises how the sociological, political and institutional influences "shape and reshape the emotional landscapes of teaching for good or ill". In any country, the state exerts some form of control over its citizens. Maturana and Varela (1998:199, in Horn 2008) suggest that a continuous strong state control breaks the will of people to take responsibility. Lefebvre (1991) has also argued that the state sells itself as the stable centre of a society when, in fact, it is not. The state's techniques, plans and programmes provoke opposition and its power is fraught with subversion. State control also encourages sameness and discourages difference, because difference in thought and action is often difficult to control (Lefebvre 1991). Marshall (1964, in Barbalet 2001:70) argues that the resentment that people feel towards state control is vested in the structural relations of the "creation and reproduction of 'social levels'". These have consequences for a person implicated by them, specifically consequences for emotional experience. Marshall (1964, in Barbalet 2001) further argues that "interactions between individuals (as opposed to structural relations) may account for certain inequalities but not social levels, certain advantages but not privilege, and some unequal exchanges but not oppression".

In addition, Mezirow's $(1991,1995,1996)$ transformative learning theory argues for a process of becoming critically aware of implicit assumptions and expectations in oneself in relation to others. According to Mezirow (1995), there are three dimensions to transformative learning, namely psychological, convictional and behavioural. The 
circumstances for transformative learning are a result of what Mezirow (1996:163) calls a "disorienting dilemma". This dilemma can appear in the form of a crisis in a person's life or as a process of multiple meaning-making transformations that unfold over a longer time. Shifts in perceptions and attitudes, especially as they relate to race, gender or religion, are often experienced as very emotional, and one therefore can expect some resistance to these shifts in students, learners and lecturers.

The necessity for acknowledging the role of emotional knowledge as interconnected to pedagogical content knowledge is also argued for by Zembylas (2007a:355). By acknowledging the importance of emotions, the methodologies of studying emotions in education should, according to Zembylas (2007c:57), also receive attention. Zembylas (2007c:59-66) consequently suggests three approaches of theorising emotion and their implications for educational research. He refers to emotion as an individual experience, a sociocultural experience, and emotion as an interactional and performative experience. The interactionist approach (a term borrowed from Savage 2004) proposes including the bodily and a sociocultural context so that emotions are not only private or a reaction to social structures, "but are embodied and performative; that is, the ways in which we understand, experience, perform and talk about emotions are highly related to our sense of body" (Zembylas 2007c:57). Zembylas (2007c:67) therefore recognises that "emotions play an important political role in enabling resistance and transformation".

Returning to the South African position, we propose that the colonial and apartheid past have left scars of different degrees and forms on people of all races and cultures. Such scars, however, can potentially have a positive or negative influence on learning. From a curriculum point of view, harm from the past needs to be taken into account by looking at the type of content that is presented, the way it is presented and the environment in which it is presented. Even if such sensitivity is present and students are not psychologically ready to participate, transformative learning will not take place. Lecturers could argue that it is not of their concern if students are psychologically unprepared to learn, as they can easily work with those students who are ready and prepared. But, with South Africa's complex history, that of abusers and abused, of the economically and socially challenged, there is essentially little other option than to incorporate processes that allow students to become psychologically ready to learn within transformative curricula.

The implication that psychological readiness in critical citizenship education extends beyond students is a stark reality in South African universities. In the same way that we need to consider a student "readiness", we also cannot simply assume that lecturers are psychologically ready to facilitate learning in critical citizenship 
education. Steyn (2006, in Leibowitz 2012) asks to what extent lecturers are able to teach critical citizenship when they themselves are products of an unequal and divided past. Jansen $(2009: 51,258)$ also debates the issue of "indirect" and "troubled knowledge" in educators and one may link this knowledge to Bozalek's (2004:71) claim that the so-called privileged of racial, gender or class "neither recognise nor take responsibility for their own privileges or the other's lack of such privileges". Curricula promoting critical citizenship should therefore incorporate learning spaces where lecturers and students could come to terms with the past, both those being discriminated against and the discriminators, in ways that Jansen (2009:264) refers to as "disrupting settled ways of knowing". The learning referred to by Jansen imply spaces where open conversations can take place in safe and non-threatening environments.

Against a background of a colonial and apartheid past, individuals and groups were "othered", stereotyped, disempowered and deprived of human rights for the sake of selfish gains. Such practices still often continue in implicit and subtle ways at South African universities across the spectrum. In trying to address the psychosocial aspects influencing teaching and learning practically in a classroom, several views of learning, including its psychosocial and transformational elements, could be useful. The intra-personal struggles of individuals as well as the inter-personal struggles embedded in society should therefore be fully recognised and dealt with (also see Fenwick 2001). Linked to the latter struggle, the next section explores elements of socio-political learning theory as underpinning critical citizenship education in curricula.

\section{SOCIO-POLITICAL ELEMENTS OF LEARNING}

We consider the "political" curriculum and its social-political elements of learning as an essential topic for exploration in this section because of the history of South African universities. In the apartheid past, some universities were used to promote, for instance, notions of Afrikaner nationalism. For instance, on 8 November 1876, De Zuid-Afrikaan, one of the earliest mouthpieces for Afrikaner nationalism, announced a lofty ideal for learning within the so-called Afrikaner community: "Hy moet nationale selfrespect leeren" (He [the Afrikaner] needs to learn national self-respect), and the decision was taken to make school and university teachers the vehicles or the carriers of nationalist messages (Nel 1979:4). By the early 1900s, Afrikaner politics, religion and education at all levels were well intertwined. Afrikaner sentiments were inspired by fear and hatred of colonial powers, culminating in the Anglo-Boer War between 1899 and 1901, whereby more than 30000 Afrikaner women and children (but 
also large numbers of black people who supported them) lost their lives in British concentration camps. After the war (1902-1910), and especially after 1910 when South Africa became a Union, anti-colonial or anti-British sentiments increased and eventually led to the defeat of the pro-British political powerbase. Nationalist politics were influenced by what happened in nationalist Germany in the 1930s and by World War II itself in the 1940s. Drs W.M. Eiselen and Hendrik F. Verwoerd, considered the architects of separate education in South Africa, had also studied in Germany and adopted sentiments of Nazi philosophy (Yeboah 2008). After 1948, the reigning National Party provided for a different emphasis: racial politics instead of anti-colonial politics. These historical incidents produced and shaped the earlier vision and mission of higher education institutions such as Stellenbosch University and others. Because education has powerful persuasive abilities, and because lecturers can be used as the carriers of these powerful messages, any education project is political by nature. It is not only the transformation of the individual that will enable a society to transform, but also the ways in which the individual will influence others to transform.

With the statement "the political is always pedagogical" Helfenbein and Shudak (2009:8) suggest that lecturers have a duty to teach students to care, and also to teach them what to care about; to "engage in the battle [...] of ideas". As a lecturer one has to accept this burden of "intellectual and moral responsibility concerning the instruction in and of democracy" (Helfenbein \& Shudak, 2009:8). If education is political, educators are also politicians; a responsibility that is not always considered, because educators are not held accountable for their "political" activities. Apple (2010:658) as well as Giroux (see Chapter 2) argue that education is not a neutral, technical activity. Rather, as an act of influence, it must be seen as an ethical and political act. Often, these informal aims are not written into the formal curriculum and therefore reflecting on the content of one's own informal teaching is crucial: Are we directing thinking or opening up spaces to develop critical thinking? Apple (2004:32-33) has observed that "the state may legislate changes in curriculum, evaluation, or policy [...] but policy writers and curriculum writers may be unable to control the meanings and implementations of their texts. All texts are 'leaky' documents". Post-modernism and post-structuralism stress the unstable, partial and contingent nature of knowledge, whereby layers of meaning are created with multiple interpretations. Knowledge is not detached from the individual, but closely related to personal experiences and emotions (Apple 1979).

Understanding the curriculum as a political text constitutes a large proportion of research and scholarship in the curriculum theory field. Pinar and Bowers (1992) refer 
to major theorists such as Freire, Giroux, Apple and McLaren as prominent examples or proponents of the political curriculum. Freire has argued that the curriculum should position the social, cultural, political, economic and philosophical critique of dominant power at its centre (see Steinberg 2010:382). Giroux (1985) and Apple (1997) both borrowed from critical theory concepts to focus on the curriculum as medium of cultural and ideological reproduction, but also as medium of resistance. McLaren (1986) has analysed ways in which power relations are reproduced through the hidden and null curricula, but also points out how cultural reproduction may be resisted and rebelled against by lecturers and students.

Weedon (1987) refers to education systems as the heart of power mechanisms because they satisfy the demands of the dominant group, as exemplified in the values and preferences espoused by any particular educational institution. At such institutions, textbooks and learning activities may not be void of religious, cultural or political influences. Apple (1979) argues strongly for this position when he says that educational texts are very often shaped to be acceptable. Curricula are shaped in complex and subtle ways by cultural perceptions and political expectations, or as Giroux (see Chapter 2) has pointed out: Curricula are not neutral.

Barnett and Coate (2008) even postulate the existence of a curriculum within a curriculum. The curriculum in theory, and the way it is presented in practice, can be two very different entities. Parts of the curriculum are therefore consciously or unconsciously hidden. No wonder that Eisner (1985:97) refers to three types of curricula, namely explicit, implicit and the null curriculum - the explicit being the published curriculum, the implicit the promotion of values and norms outside the published curriculum and the null curriculum referring to what is not offered, implying choices that are not presented to students and viewpoints they are not exposed to.

Curricula that promote political aims usually have roots in Marxist philosophy that is aimed at changing the world as an alternative for merely interpreting it. For Null (in Connelly, He \& Phillion 2008), curricula represent social and political activities that require judgement and action, while Apple (1990) suggests a radical transformation of public education institutions to prevent a perpetuation of inequality, racism, classism and genderism. Critical pedagogy in curricula therefore supports Shor's notion of critical teaching that is aimed at critical reflection and active transformation, instead of mere interpretation (1980, in McLaren 1994).

Ellison (2009:333), referring to McLaren, argues that in order to "demystify" the "oppressive social relations that it fosters", curricula should promote the development of a "revolutionary class of educators and citizens" and that internal contradictions of capitalism should be made apparent. Furthermore, Ellison (2009:333) argues that 
this is a noble struggle where educators should help students develop a specific type of "dialectical knowledge in very specific settings that will bring forth revolutionary possibilities". Others believe in liberal curricula that have a social point of view and address, among others, the unequal distributions of wealth and political economy as well as manifestations of oppression (Watkins 2010:301). All of such curriculum aims clearly have political undertones.

Moreover, universities are often infested with hidden, or sometimes openly promoted, political power structures that will not come to be exposed if not unpacked and addressed in a critical manner. The deep roots of colonial imperialism and the apartheid system that followed it have left traces that were not wiped out by a new South African constitution after the first democratic elections in 1994. Therefore, responsibility for enabling social transformation not only lies with the politicians, policy decision makers and the authors of educational white papers, but with the people who interpret those policies and papers. The agency of lecturers can therefore not be stressed enough, as they act as the medium or translator of the curriculum messages in an evolving democratic higher education dispensation.

During the colonial and apartheid past, Western culture was seen as the norm from which all other cultures deviated. This is still valid to a certain extent in some contexts today. The culture that is considered "normal" is seen as a backdrop against which all other "values, culture and knowledge are to be measured" (Apple 2010:658-659). Currently, Western culture, associated with capitalism, materialism and consumerism, is advertised and disguised under the notion of popular culture, and still dominates in South Africa. Systems therefore work much better for students who identify with the "normal" culture, especially if they already possess cultural and economic capital (Apple 2010:658-659).

Snyman (2008:421) remarks that, as long as "whiteness" is not critically analysed by white people themselves, the perception of white as "the norm" will not change in certain circumstances. In many of his speeches, South African ex-president Thabo Mbeki emphasised the dominant role of whiteness in our thinking, commenting on the perceived, automatic power that is connected with white in contrast to the perceived, disempowerment connected with black. ${ }^{3}$ Snyman (2008:421) also specifically remarks that whiteness needs to analyse a Christian heritage critically, because of its link with the notions of imperialism, conquest and colonialism that fed racism. Jansen (2009) highlights the idea that colonialists were seen as "God's chosen people on a civilising mission". The classification of others as pagan was

3 In opposition to this argument, with a new dominant culture come new forms of political and social domination, and blackness as the norm is becoming more prominent. 
introduced in order to "uplift" them. This classification and projection of the other as non-Christian, merged with class and language differentiation, later became part of the basis for racial divisions.

However, in modern-day "liberated" South Africa (the so-called post-Mandela era), class domination poses a new and material threat (Jones 2013). A new black elite has emerged, convinced that they are entitled to new forms of domination - particularly in terms of entitlement to economic privileges previously enjoyed by the white elite. In the process, corruption, nepotism and political arrogance dominate widely and some members of the new black elite believe that their newly found political power will be endless - in the process not looking after the educational, material and other needs of millions of un- and underprivileged citizens who were also disadvantaged through political dispensations such as apartheid.

In the latest (2014) South African elections, a new and relatively unknown political party catering for "the workers and the poor" has in a short space of time attracted 25 parliamentary seats, while the official opposition has made substantial inroads in the voter support base of the current governing ANC party. Offspring of the privileged "rich black" increasingly attend universities and find themselves in similar positions than the offspring of privileged white people, who may not have much of an idea of being discriminated against. These are all indications that a new political and social discourse and reality is opening up in South Africa, one that looks into class as a political issue and that may inevitably influence how universities see their roles in society and, importantly, how they enact such roles through their curricula, their teaching and their research (Smith 2014; The Citizen 2014).

It seems clear that the socio-political elements of curriculum theory not only aim to bring hidden discourses to the surface, but also include a call for action in student learning. Cohen, Manion and Morrison (2007:27) seek to establish how educational institutions maintain or reduce inequality that is again reproduced in society, how power is produced and reproduced through education, who benefits from this power and how legitimate these preferences are. Because of its very nature, one can argue that the aim of critical theory in education is transformative: to transform individuals towards participating in a democratic society. It should, however, be noted that these actions might be suppressed, or take place unconsciously or subliminally, and that this could perpetuate a system to sustain the status quo of the empowered and disempowered.

In literature, socio-political discourse also dissolved into other related discourses, such as citizenship education (Johnson \& Morris 2010; Nussbaum 2002, 2006) and post-colonial studies (Asher 2005; Dimitriadis \& McCarthy 2001). These 
issues are further explored in the next section on the multicultural curriculum and student learning.

\section{MULTICULTURAL ELEMENTS OF LEARNING}

It is quite common knowledge that in parts of the world, a strictly Marxist focus on class was slowly replaced by "new pan-ethic-cultural orthodoxies of racial origins and racial identity" (McCarthy \& Crichlow 1993:xiv, in Pinar 2008). In this sense, the "multicultural curriculum" represents and examines socio-political, historical and cultural contexts. It focuses primarily on ethnicity, race and culture, and secondarily on class, gender and sexuality in relation to issues such as discrimination, social justice and power relations. The unifying goals for the multicultural curriculum are therefore to create a socially just education system for diverse students through social transformation (Phillion 2010).

In South Africa, during apartheid and currently continuing to some extent, the focus was, and still is, not only on race, but also on the skin colour of people. This may partly be the result of prolonged periods of colonial domination whereby experience was internalised and implanted in the subsoil of both mind and body of generations to come (Fanon 2006). During apartheid, colonial supremacy continued, but with an additional focus on ethnicity and colour. Public institutions were separated on the basis of colour. A child from a white and a black parent would have been classified as coloured, which meant the child had to attend a coloured school and not a white or a black school. The embodiment of racism in South Africa is highlighted by Ratele and Duncan (2007), who also refer to Foucault, who suggested that even when a system is unjust, people can construct themselves to fit the mould, and therefore "hand themselves over" to access power.

Foucault (1995:136) has warned that people can be turned into objects of knowledge and can be "trained" and "disciplined" to produce themselves as entities to be "subjected, used, transformed and improved". Power not only functions on a political basis, but, according to Foucault, also through social patterns. A telling example of this in the South African context was clearly seen in situations where people applied to be reclassified from black to "coloured" (brown) or "coloured" to white. The colour differentiation of white, coloured (brown) and black gave access to different levels of power. Whiteness became associated with the highest hierarchy in power and blackness with the lowest. Ironically, recent xenophobic attacks in South Africa on people from central Africa who have a darker complexion and are therefore seen to have a lower status can be seen as a repetition of ingrained hierarchies of the past (Palmary 2002:4). 
Cultural pluralism and equal opportunity are the main pillars of multicultural curricula (Grant \& Sleeter 1994:170). In the USA, principles regarding multiculturalism have been formalised in the human rights constitution as how it ought to be, but the theory of social systems or human psychology has not been extensively investigated (Jacobsen 2003). While equal opportunity is a legal and democratic right formalised in the South African human rights-based constitution, cultural pluralism is a more nebulous theoretical concept that deals with aspects of assimilation and amalgamation between majority and minority groups.

The multicultural curriculum has been developed to accommodate diverse students to close the achievement gaps among students from different cultural or ethnic groups. Gay (2010:587) argues that this is a "logical premise to make because race, ethnicity, class, culture, and education are deeply interconnected". Learning about different ethnic, race or cultural groups is not the only focus in the multicultural curriculum, as it is also important to reflect on racial perceptions, attitudes and values of the past and to imagine a just future (Gay 2010). Factual teaching, as in transmission of facts, is much less complex and less emotionally challenging than addressing values, perceptions and attitudes. As summarised by Apple (2010:660), it simply "[t]ell[s] the truth about exploitation and domination". Pinar (1991) argues that the Eurocentric curriculum prevents non-white students from having role models and disallows white students to come to understand themselves in context, while also exploring the curriculum as a racial text, seeing the lack of diversity in knowledge systems incorporated in curricula as academic racism.

There are, however, inconsistent views regarding the value of multicultural learning in curricula. McCarthy (1991), for instance, describes multicultural education as often contradictory and a challenging solution to racial inequality. He argues for inclusion of different cultures in a curriculum, more sensitivity and understanding of ethnic differences in the classroom, and competence of languages and culture outside educators' and students' ethnic affiliation.

Schuitema, Ten Dam and Veugelers (2008:73) refer to Parker (2001), who has observed a gap between citizenship education and multicultural education. Parker argues that diversity is regarded as a threat to unity in the field of citizenship education, while the issue of diversity is relegated to multicultural education. In this vein, Weinstein (2004) points to an emphasis on teaching difference and not stressing social cohesion or social harmony, and valuing difference therefore becomes an important factor in citizenship education.

In South African curriculum development, several researchers (Hoberg 2004; Kamwangamalu 1999; Le Roux 2000; Nakusera 2004; Van Wyk \& Higgs 2004; 
Venter 2004; Waghid 2004) have argued that the African philosophy of learning can be used to enhance multicultural educational curricula. Venter (2004:156) argues for the inclusion of the ubuntu 4 view in education, but she also argues for the teaching of "humanity" and calls on educators to teach humanity with an emphasis on humanness instead of race. Mapesela (2004) asks whether indigenous knowledge is understood well enough to be included in the curriculum, and stresses that indigenous knowledge changes all the time with changing circumstances (also see Remenyi 2007). Bitzer (2001), in a case study, has also looked at how promoting cooperative learning with students may tie into the concept of ubuntu.

To realise the multicultural curriculum in practice, various options exist. For instance, Grant and Sleeter (1994:176) include explanations of assimilation and amalgamation models, as well as classical and modified cultural pluralism. Newman (1994 in Grant \& Sleeter 1994:177-179) uses the formula "A + B + C = A" to represent an assimilation model, where the minority ( $B$ and $C$ ) is dominated by the majority (represented by " $A$ "). Amalgamation, whereby all the groups are synthesised into a new group, is represented by " $A+B+C=D$ ", where " $D$ " is the new synthesised group. If this theory is to be successful in practice, all the groups should be of equal status and willing to amalgamate. Classical cultural pluralism theory states that cultural groups maintain their identities ("A $+B+C=A+B+C^{\prime \prime}$ ) and modified cultural pluralism expands on this by stating that cultural diversity will continue to exist in spite of attempts to assimilate or amalgamate.

At a workshop on complexity theory at Stellenbosch University in 2011 , Hofmeyer (2011) referred to the work he and Cilliers ${ }^{5}$ were doing prior to Cilliers's death. Looking at Newman's equation, their research primarily dealt with how to change from $A$ influencing $B$ and the result being $C$, to $A$ becoming part of the factors that are influenced and so becoming an open system where all are influenced by all. Interactions in classroom learning situations would therefore not only be influenced by the dominant group or lecturer, but all groups or individuals should have the potential to influence one another. If a lecturer and a student both taught each other and learnt from each other to discover new perspectives, discovery in the multicultural model of learning would become greatly rewarding.

4 Ubuntu means "humanness" when translated. Mbiti (in Van der Walt 1997:33) explains the concept of ubuntu as "I am because we are, and since we are, therefore I am", which relates to the expression "a person can only be a person through others".

5 Paul Cilliers was a professor of Complexity and Philosophy at the Centre for Studies in Complexity at the Department of Philosophy at Stellenbosch University. He died on 31 July 2011. 


\section{CONCLUSION}

In this chapter we have emphasised that higher education curricula need to be actively engaged to become and remain vibrant within an evolving democratic dispensation such as in South Africa. We have also proposed that critical citizenship education is a worthy perspective to adopt when engaging curricula against the background of what public universities in South Africa should achieve, given its colonial and apartheid past. In promoting critical citizenship education in curricula we propose at least four elements of learning to inform such education, namely learning that draws on psychosocial, transformational, socio-political and multicultural learning. All such learning point to curricula that enable students and lecturers to gain new, but sometimes discomforting, perspectives. It also suggests curricula that promote non-conforming institutional and psychological learning spaces, taking into account past and current political and societal challenges. What becomes evident is that, as stated in the introduction to this chapter, engaging curricula via critical citizenship requires an involved perspective. What we also came to realise is that the forces interacting and competing for power in such curricula are evolving and complex.

In Chapter 5 we present a case study in critical citizenship education. This case involves a closer look at a critical citizenship module that was initiated by the Department of Visual Arts at Stellenbosch University. Much of what we have discussed up to now will become even clearer in interrogating this case, presented as an example of an integrated approach to critical citizenship education in an undergraduate Visual Arts curriculum. 